\title{
EL PATIO DEL VERGEL DEL REAL MONASTERIO \\ DE SANTA CLARA DE TORDESILLAS Y LA ALHAMBRA DE GRANADA. REFLEXIONES PARA SU ESTUDIO
}

\author{
Juan Carlos RuIz SouZA* \\ Universidad Autónoma de Madrid
}

Las circunstancias que rodean el estudio de la arquitectura civil son en gran medida mucho más complejas que las que encontramos ante los edificios religiosos. Estos últimos presentan esquemas planimétricos muy repetitivos, debido a las necesidades litúrgicas; además, su continua utilización ha posibilitado la conservación de gran número de ejemplos. El estudio de las casas y los palacios hace necesaria la utilización de otros parámetros. En primer lugar, nos encontramos ante unas manifestaciones en las que los promotores, sus gustos, o simplemente la topografía y el clima del lugar, han permitido una mayor libertad de planteamientos ${ }^{1}$. Por otra parte, tenemos proporcionalmente muchos menos restos, y casi siempre bajo una serie de circunstancias muy especiales que podemos resumir principalmente en dos. Si el edificio no ha perdido su funcionalidad civil, su utilización ha hecho que sufra continuas reformas y restauraciones que han deformado su aspecto primitivo en gran medida, dependiendo de la diversidad de modas y criterios utilizados en cada intervención. En este primer grupo estudiaríamos los dos hitos más relevantes de nuestra arquitectura áulica bajomedieval: la Alhambra y el Alcázar de Sevilla. En cambio, y como peculiaridad netamente hispánica, muchas casas y palacios han llegado a nosotros al haber sido reconvertidos por sus dueños, desde tiempos remotos, en conventos de clausura. Gracias a ello contamos con un buen número de edificios, cuya pervivencia sólo se explica por el cuidado y mantenimiento continuado ejercido por las comunidades que han habitado entre sus muros. A veces es posible hallar construcciones muy poco intervenidas, en las que los testigos primitivos del palacio han quedado ocultos bajo obras

\footnotetext{
* En estos momentos nos encontramos ultimando una tesis doctoral sobre Aproximación a la arquitectura del siglo XIV de la Corona de Castilla y del Reino de Granada, bajo la dirección del dr. Isidro G. Bango Torviso.

${ }^{1}$ Poco a poco, y sobre todo en los últimos años, el estudio de este tipo de construcciones ha ido en aumento, pudiéndose destacar principalmente los trabajos de A. Almagro, J. Navarro, A. Orihuela y P. Jiménez, entre otros, porque además de realizar una importante labor de investigación han mostrado un gran interés por presentarnos un exhaustivo aparato gráfico, en muchos casos por primera vez.
} 
posteriores, tal como ocurre con los vestigios aparecidos recientemente en Santa Clara de Tordesillas.

Centrándonos ya en nuestro convento, los trabajos llevados a cabo en $1988^{2}$ sacaron a la luz unos interesantes restos en el jardín del Claustro del Vergel ${ }^{3}$. M. ${ }^{a}$ Luisa Bujarrabal y José Luis Sancho interpretaron la existencia de unos templetes avanzados en sus lados cortos, que rematarían los extremos de su eje longitudinal $(\mathrm{E}-\mathrm{W})^{4}$, y en cuyo centro ubicaron la cimentación de una posible alberca octogonal. Esta última, a su vez, se encontraba unida mediante una canalización, que discurría por el eje arriba citado, con el Salón del Aljibe, en la panda oriental del patio, en cuyo centro se encuentra otra fuente. Ambos autores también llamaron la atención sobre la existencia de un estanque cuadrangular bajo la alberca y la ausencia de restos o cimentaciones que pudieran evidenciar un eje transversal.

Pérez Higuera prefirió la posibilidad de que nos encontrásemos ante un patio de crucero, pudiendo ser el ochavo central la prueba suficiente de la posible existencia de ese brazo perpendicular ${ }^{5}$. Es cierto que la planta de crucero es una de las fórmulas más corrientes en la arquitectura peninsular; baste recordar los ejemplos de Madīnat al-Zharā', de Monteagudo en Murcia, el de la Casa de Contratación en Sevilla ${ }^{6}$, o el del Alcázar Cristiano de Córdoba entre otros. Por otra parte, considera más apropiado interpretar como albercas los cimientos extremos del eje longitudinal, en lugar de los pabellones adelantados. Es cierto que en la mayoría de los edificios civiles hispanomusulmanes conocidos suele ser habitual la utilización de albercas, pero ello no quiere decir que no existan otras soluciones.

\footnotetext{
${ }^{2}$ Bujarrabal, M. ' L., y Sancho, J. L., "El palacio mudéjar de Tordesillas», Reales Sitios, 106 (1990), 32. Además publican una fotografía de la excavación del Patio del Vergel.

${ }^{3}$ Las dimensiones del patio son $24,15 \mathrm{~m}$ por $36,51 \mathrm{~m}$, teniendo las cuatro galerías una anchura de $4,18 \mathrm{~m}$, por lo que el jardín interior presenta unas dimensiones de $19,97 \mathrm{~m}$ por $32,33 \mathrm{~m}$. Son unas medidas importantes; por ejemplo, el Patio de los Leones de la Alhambra cuenta con 28,5 m de largo por 15,7 m de ancho. Llama la atención el parecido existente con el patio del Alcázar de Córdoba, que mide $24,2 \mathrm{~m}$ por $37,8 \mathrm{~m}$.

${ }^{4}$ Lavado Paradinas, P., "Palacios o conventos: Arquitectura en los monasterios de clarisas de Castilla y León", Actas del Congreso Internacional: Las Clarisas en España y Portugal. Salamanca 20-25 de Septiembre de 1993, Madrid, 1994, II, 729-734, y “Mudéjares y moriscos en los conventos de clarisas de Castilla y León", VII Simposio Internacional de Mudejarismo (Zaragoza, 1996), 391-419. Sin entrar en más detalle, tomando los datos del artículo de Bujarrabal y Sancho, apunta sobre el recuerdo al Patio de los Leones de la Alhambra del Patio del Vergel, ante la utilización de pabellones enfrentados.

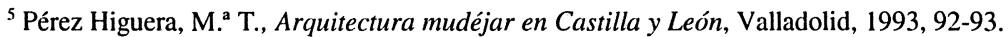

${ }^{6}$ Véase Vigil Escalera, M.; Abad Gutiérrez, J., y Martínez García-Otero, S., El jardín musulmán de la antigua Casa de Contratación de Sevilla, Sevilla, 1992, 2 vols.
} 
Detengámonos un momento en el interesante ejemplo del Castillejo de Monteagudo de Murcia, erigido en el tercer cuarto del siglo XII. La polémica en torno a su patio de crucero es un elemento que hay que tener en cuenta para ver hasta qué punto un edificio de semejante importancia no ha contado con unanimidad en su estudio. Torres Balbás ${ }^{7}$ lo estudió en 1934, interpretando su patio con dos pabellones enfrentados en el eje mayor del crucero. Gómez Moreno, años más tarde, prefiere la solución de las albercas, y Torres Balbás, al retomar el tema, sin negar lo defendido en su primer trabajo, al que nos remite, no nos dice nada de los pabellones ${ }^{8}$. En 1995 Julio Navarro Palazón y Pedro Jiménez Castillo ${ }^{9}$ publican el último y más completo trabajo referido a esta construcción y, aunque reconocen la imposibilidad de evidencias arqueológicas ante la alteración que ha sufrido el yacimiento, consideran que la hipótesis de Gómez Moreno sería la más acertada.

Respecto al tema de los pabellones, Torres Balbás establece una posible relación con los claustros monásticos y en especial con los templetes cistercienses que cobijan los lavabos fronteros a los refectorios. La aparición de estas estructuras en la Península, en edificios de ambas religiones, refiriéndose nuevamente al Castillejo de Monteagudo, y la ausencia de ejemplos conocidos en Oriente, llevan al autor a pensar en la ascendencia cristiana de esta solución ${ }^{10}$. Manzano Martos, por su parte, dedica buena parte de uno de sus últimos estudios a las diferentes articulaciones que adoptan los patios y estancias anexas de los palacios erigidos entre el período califal y el almohade. Observa en el prototipo taifa de la Aljafería de Zaragoza un posible antecedente de la solución nazarí desplegada en el Patio de los Leones, al proyectarse sobre el patio de Santa Isabel dos pabellones, en los laterales del pórtico norte, que abrazan una alberca central ${ }^{11}$. También podrían recordarnos un pabellón adelantado los restos de la cimentación encontrados en el extremo meridional del palacio del Partal, en la Alhambra, aunque no acaba de estar claro cómo se

\footnotetext{
369.

${ }^{7}$ Torres Balbás, L., "Monteagudo y "El Castillejo" en la vega de Murcia”, Al-Andalus II (1934),

${ }^{8}$ Gómez Moreno, M., El arte árabe español hasta los almohades. Arte Mozárabe, Ars Hispaniae, Madrid, 1951, vol. III, p. 281; Torres Balbás, L., "Patios de Crucero", Al-Andalus XXIII (1958), 171-192.

9 "El Castillejo de Monteagudo: Qașr Ibn Sa'd", Casas y palacios de Al-Andalus. Siglos XII y XIII, Barcelona, (1995), 83-84.

${ }^{10}$ Torres Balbás, L., "El patio de los Leones de la Alhambra: su disposición y últimas obras realizadas en él", Al-Andalus III (1935), 174-175.

1 Manzano Martos, R., "Casas y palacios en la Sevilla Almohade: sus antecedentes hispánicos", Casas y palacios de Al-Andalus, Siglos XII y XIII, Barcelona, (1995), 336.
} 
articulaba la zona elevada sobre terrazas de este edificio de la primera década del siglo XIV atribuido a Muḥammad III.

Si común resulta la planta de crucero, tampoco es extraña en la arquitectura hispanomusulmana la utilización preponderante de un único eje longitudinal (alberca o canalización), sin necesidad de realizar siempre un crucero, o quedando el brazo transversal del mismo minimizado. Importante modelo al respecto lo encontramos, una vez más, en el edificio zaragozano citado, del siglo XI, en el que las albercas fronteras a los pórticos norte y sur quedaban unidas por una canalización de agua, que marca el eje mayor en el patio rectangular del palacio. En la arquitectura nazarí de los siglos XIII y XIV, como ha estudiado Orihuela Uzal, esta fórmula no nos es tampoco ajena ${ }^{12}$.

Hasta aquí hemos hablado de ejes que existen físicamente, pero puede haber también ejes visuales. En el Patio de los Leones, junto a los dos ejes del crucero, existe un eje visual que es el más importante de todos, incluso más que el marcado por los dos pabellones adelantados: nos referimos al que une la Sala de Abencerrajes, al sur del patio, con la Sala de Dos Hermanas, junto a la de los Ajimeces y mirador de la Lindaraja, al norte de esta última. Posiblemente en Tordesillas, el eje que falta también pudiera ser visual, al encontrarse en el lado sur las estancias más importantes del recinto, convirtiéndose el eje físico, con sus dos pabellones (E-W), en un artificio que llevase la atención del visitante a las partes menos relevantes (funcionalmente) del patio, como ocurre en la Alhambra.

Volviendo a Santa Clara de Tordesillas, después de sopesar todas las fórmulas posibles, y ante la dificultad de poder ofrecer una hipótesis concluyente a la problemática del interesante Patio del Vergel, hasta que en el futuro se emprenda una excavación arqueológica, finalmente nos inclinamos a considerar que en origen contaba con dos pabellones enfrentados.

La interpretación de los restos hallados a finales de la década de los ochenta no muestra la existencia de lo que sería el hueco impermeabilizado de las albercas, ni de la existencia de material especial de aislamiento que evitase fugas de agua. Más bien parece que se trata de la cimentación de una pequeña estructura

${ }^{12}$ Orihuela Uzal, A., "Los inicios de la arquitectura residencial nazarí", Casas y palacios de AlAndalus. Siglos XII y XIII, Barcelona, (1995), 225-239, presenta numerosos ejemplos planimétricos granadinos, en el que vemos la común utilización de albercas longitudinales, tanto en patios o espacios cerrados (Palacio de los Abencerrajes, Casa de los Girones, Palacio del Exconvento de San Francisco, Palacio del Generalife...), como en espacios abiertos (Palacio del Partal...). Por último, hacemos nuestras las palabras del autor, en las que dice: "Las tendencias evolutivas en los patios deben analizarse de forma separada para cada tipo, pues es muy difícil sacar conclusiones generales válidas para todos ellos" (p. 235). 
o "pabellón", construido encima de la roca madre sobre la que se levanta todo el edificio ${ }^{13}$.

Veamos qué ocurre en otros ejemplos hispanos, bien conocidos, en los que se ha optado por la solución de las albercas. En la casa de La Alberquilla de Madinat al-Zahrā' (siglo X), en el patio de crucero de la Casa de la Contratación de Sevilla (siglo XII) y en el Alcázar de los Reyes Cristianos de Córdoba (siglo XIV) observamos dos características similares. Primeramente, nos encontramos con unos patios que sólo disponen de pórtico en sus lados menores, fórmula anterior a la desplegada en Tordesillas o en el Patio de los Leones, al contar con sus cuatro galerías porticadas. Por otra parte, en estos tres casos aparecen albercas frente a los pórticos, pero muy separadas de ellos, permitiendo un cómodo paso de circulación entre ambas estructuras. En Tordesillas, en cambio, los restos aparecidos se ven perfectamente unidos a la galería porticada, lo cual invita a pensar en una estructura adosada a ella ${ }^{14}$. A falta de más datos arqueológicos, hemos considerado que las cuatro crujías que circundan el patio tendrían como mínimo la misma anchura de las existentes en el siglo XIV ${ }^{15}$.

Otro elemento fundamental, y clave de todo lo que aquí tratamos, es la existencia de una pieza de gran importancia, tanto por su excepcionalidad como por el estado de conservación que presenta. Nos referimos al canalillo, gárgola o surtidor hispanomusulmán conservado en el monasterio, y que ha quedado olvidado (láms. 1 y 2). Aunque hoy este surtidor aparece totalmente descontextualizado en la huerta del monasterio, no creemos descabellado, a falta de otras informaciones, considerar que formaría parte de la estructuración hidráulica del Patio del Vergel, ya que por ahora nada hace pensar que pudiera pertenecer a otro lugar. De caliza, presenta una planta rectangular de 91 x $45 \mathrm{~cm}$, y una sección semicircular que oscila entre los $18 \mathrm{~cm}$ del extremo por donde entraría el agua, frente a los $21 \mathrm{~cm}$ del otro, por donde la evacuaría. Esta pieza, por sus dimensiones y por los otros ejemplos conocidos, debía poner en comunicación una pila de agua con una gran alberca $^{16}$. Los casos estudiados no dejan lugar a dudas, y no conocemos elementos

${ }^{13}$ Agradecemos a José Luis Sancho los datos facilitados al respecto.

${ }^{14}$ El patio en su totalidad ha sido muy transformado, y aunque las galerías actuales son de los siglos XVII-XVIII, sustituyeron a otras anteriores, de ladrillo, como veremos en la documentación conservada.

${ }^{15}$ Deberíamos descartar la posibilidad de que en origen fuese menor la anchura de las crujías, explicándose así que tras la construcción de las galerías clasicistas se derribaran las medievales. De esta manera, la planta rectangular que en la actualidad presentan los cimientos de los pabellones tendería a la planta cuadrada, ya que éstos avanzarían hacia las pandas del pátio.

${ }^{16}$ Sobre este tipo de canalillos, gárgolas o surtidores, véase Bermúdez Pareja, J., «Crónica de la Alhambra: Renovación de tres fuentes de la Alhambra", Cuadernos de la Alhambra 3 (1967), 183-188; id., "El agua en los jardines musulmanes de la Alhambra", Icomos. Les jardins de L'Islam, Granada, 
de este tipo ante albercas pequeñas. En el Patio de los Arrayanes vemos dos canalillos en los lados cortos del gran estanque rectangular (lám. 3), y en la alberca del Partal sólo uno de ellos, al menos desde las restauraciones efectuadas en este siglo, junto al pórtico conservado del palacio. Su función es la de evitar que el vertido del agua produzca ondas en la superficie de la alberca, para que el efecto de espejo simulado no se pierda. El complejo mecanismo consiste en que el agua que brota a través de un surtidor metálico, en vertical, del centro de la pila, se dirija a este canalillo. El agua entra por la parte más ancha de la pieza, donde el canal adopta forma circular; después éste se va estrechando pasando el líquido por encima del relieve de dientes de sierra que, a modo de contra ondas, evita que se vierta violentamente sobre la alberca, antes de lo cual la canaladura se estrecha nuevamente. Además esta gárgola presenta una ligerísima pendiente ${ }^{17}$ ascendente que dificulta la circulación del agua, produciéndose cierta tensión con la que, a su vez, entra por la boca del canal desde la alberca. Cuando se trata de estanquillos de pequeñas dimensiones, el mecanismo de una gran gárgola carece de sentido, optándose sencillamente por una pequeña canalización realizada incluso con ladrillos. Son muchos los ejemplos que de este último caso pueden aún rastrearse en la ciudad de Granada y, aunque en buena parte hoy vemos el fruto de restauraciones, todo hace pensar que en origen encontrásemos iguales soluciones en el palacio de Daralhorra o en la casa de Zafra.

Además de esta gárgola, existe una pequeña pila de mármol (láms. 4 y 5), posiblemente traída de algún palacio andalusí, de $59 \mathrm{~cm}$ de diámetro y $16 \mathrm{~cm}$ de altura. Junto a su borde exterior, una cinta rematada por unos nudos configura la única decoración de la pieza. En su centro, un agujero prueba que dicha pila se encontraba en contacto con conducciones de agua. Como veremos, pensamos que podría situarse sobre la fuente del Salón del Aljibe ${ }^{18}$.

Desgraciadamente, no contamos con demasiados datos sobre la intervención realizada en el Patio del Vergel durante la década pasada. Una vez más, solamente el artículo de M. ${ }^{a}$ Luisa Bujarrabal y José Luis Sancho nos brinda la descripción de lo que apareció ${ }^{19}$. En la actualidad se ha dejado visible la articulación de todos

1976, 190, y Kugel, C. M., "Agua y Arquitectura. Agua y Jardín. Naturaleza y vida en tiempos nazaríes", Arte islámico en Granada, Granada, 1995, p. 109.

${ }^{17}$ En el caso de la pieza conservada en Tordesillas, ya hemos dicho que en la parte por donde entra el agua desde la pila presenta una sección de $0,18 \mathrm{~cm}$, frente a los $0,21 \mathrm{~cm}$ del otro extremo. Es decir, vemos una pendiente paulatina de tres centímetros a lo largo de $l o s 91 \mathrm{~cm}$ que mide la gárgola.

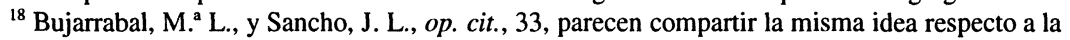
ubicación de esta pila.

${ }^{19}$ Ibid., 32. 
los hallazgos a través de los distintos elementos que, tras la restauración del conjunto, marcan una serie de áreas bien diferenciadas en la superficie del jardín.

Junto a las estructuras anteriormente citadas y que se vinculan a los pabellones, como se ha dicho más arriba, apareció una conducción que unía la crujía oriental del patio con el centro del mismo, en donde se halló también la cimentación de una especie de estanquillo octogonal. En cambio, no apareció otra canalización similar a la anterior y que a su vez comunicase con el pabellón frontero en la parte occidental del claustro. Junto a todo lo comentado, como ya vimos, se encontró también la cimentación de un estanque cuadrangular junto a la ochava $a^{20}$ del centro del patio.

Realmente resulta muy complicado poder llegar a una solución que explique todas las cuestiones arriba sugeridas; tan sólo podemos plantear unas hipótesis con sus fundamentos. Problemas que se suman a la dificultad de poder datar todos los restos aparecidos, e incluso afirmar si todos ellos son coetáneos, y más cuando sabemos por la documentación que desde tiempo antiguo se intervino en toda esta zona del monasterio ${ }^{21}$.

El convento se asienta sobre la roca viva, en un terreno que presenta una pendiente descendente de $\mathrm{W}$ a $\mathrm{E}$. El drenaje del claustro con las lluvias era complejo, siendo muy corrientes las inundaciones ${ }^{22}$.

${ }^{20}$ Ibid.

${ }^{21}$ Toda la parte del jardín del Claustro del Vergel ha sido intervenida en diversas ocasiones a lo largo del tiempo. En el Libro de distribución de rentas de maravedís del Real Convento de Santa Clara, que comienza en 1789, al dejar constancia de las obras realizadas en el almacén y gradas el 22 de julio de 1792, se comenta lo gastado en "...sacar la piedra de un pozo que se descubrió en el Vergel..." (Archivo del Convento de Santa Clara de Tordesillas, apartado de obras, folio 439 vto., libro sin inventariar). Desgraciadamente, el documento no nos dice más. Aunque no se explicita cuál fue el destino de la piedra, es muy posible que se utilizase en reparar muros del convento o la misma cerca que lo circunda, ya que continuamente se alude a obras de este tipo. Respecto al descubrimiento del pozo, tampoco podemos añadir más. Es extraño que fuera desconocido y aparezca en estos momentos; tal vez hubiera que ponerlo en relación con la infraestructura del palacio... Asimismo, son continuas las referencias a la limpieza y reconstrucción de conductos de agua; veamos alguna. En el Libro de la Distribución de las rentas de maravedís deste Real Convento, que comienza en 1794 (Archivo del Convento, fol. 424 rto., libro sin inventariar), se realiza un pago al maestro de obras Manuel Díez, el 19 de febrero de 1797, por reparar las bóvedas necesarias. En el Libro de distribución de maravedís que comienza en 1802 (Archivo del Convento, fol. 404 rto., libro sin inventariar), se reflejan las obras que en enero de 1804 se realizan en los conductos de las necesarias. En el Libro de distribución de las rentas de maravedís de este Real Convento de Santa Clara, que comienza en febrero de 1822 (Archivo del Convento, fol. 323 rto., libro sin inventariar), se registran una serie de pagos al maestro de obras del 21 de marzo al 4 de julio de 1824 por el reparo del conducto de las necesarias. Aunque no sabemos dónde se ubicarían exactamente las necesarias, parece lógico pensar que éstas estuvieran situadas en la parte noroccidental del claustro, cerca del refectorio, cocinas y dormitorio, pudiendo sus conducciones afectar de alguna manera al subsuelo del patio en su circulación hacia el río.

${ }^{22}$ Bujarrabal, M. ${ }^{a}$ L., y Sancho, J. L., op. cit., 32, llaman la atención sobre este mismo punto. 
Parece extraño que sólo haya aparecido en el eje E-W del patio la conducción que desde el centro se unía con la crujía oriental del recinto. Es raro también que alrededor del ochavo central haya también la cimentación de otro estanque de planta cuadrangular. Por último, no se conoce ejemplo alguno en que una gárgola, como la conservada en el monasterio, de grandes dimensiones, no comunique con una gran alberca.

En el mundo andalusí el agua fue manejada con un virtuosismo casi inimaginable, aprovechándose su simple conducción para producir interesantes efectos estéticos, mediante corrientes y albercas, y ambientales, al servir su presencia para regular la temperatura y la humedad de los espacios tanto abiertos como cerrados. Baste recordar la gran obra de ingeniería hidráulica existente en la Alhambra y Generalife, con su Acequia Real, que procedente del río Darro fue en un principio planeada para abastecer la Alcazaba, la parte del recinto más occidental y baja de todo el conjunto arqueológico. También sabemos cómo el proceso de ocupación en la colina de la Šabīka hacia cotas más elevadas se solucionó con extracciones de agua de la gran acequia, mediante profundísimos pozos, norias y albercones, que permitían disponer del preciado elemento en las partes más altas de la colina ${ }^{23}$.

¿Cómo se solucionaba el problema del abastecimiento de agua en nuestro palacio vallisoletano? Al oeste de todo el complejo constructivo, en la actual huerta, en el extremo noroccidental de esta zona, se conserva un gran pozo. Aunque no podemos datarlo, todo hace pensar que pudiera ser el origen del agua necesaria para la vida del edificio ${ }^{24}$. Casualmente, cuando la regia residencia pierde su carácter civil al fundarse el cenobio en 1363, las cocinas se ubican en la parte del palacio que se encuentra más próxima a la referida extracción. Fórmula, por otra parte, común en la práctica totalidad de nuestros monasterios medievales, en los que su topografía se veía claramente determinada por la situación de las corrientes de agua, siendo la zona de cocinas la que, por necesidad, se encontraba en la zona donde todavía no se había contaminado por otros usos.

\footnotetext{
${ }^{23}$ Malpica Cuello, A., "El complejo hidráulico de los albercones», Cuadernos de la Alhambra 27 (1991), 65-101.

${ }^{24}$ Agradecemos a don Javier García Gallardo, arquitecto de Patrimonio Nacional, la información que nos facilitó sobre dicho pozo. Lavado Paradinas (1996, p. 393) considera que el agua llegaría al convento desde otro pozo ubicado en el ángulo nororiental del monasterio, siendo canalizada hacia la actual cabecera de la iglesia. Consideramos que dicha extracción tendría un carácter secundario, al encontrarse en una cota inferior respecto al otro pozo y a la zona occidental del palacio (ver croquis). Su utilización sería dificultosa ante la problemática de subir el agua a las cocinas (junto a la Capilla dorada) o al propio Patio del Vergel. Posiblemente, su uso sólo estaba destinado a los baños del palacio.
} 
En primer lugar, creemos que el agua que se utilizaba en el palacio se tomaría de ese pozo al que hemos hecho mención más arriba. Seguramente mediante una noria de tracción animal era almacenada en una especie de albercón o gran aljibe, ocupando parte de la actual huerta.

En un segundo paso la conducción se dirigiría hacia el E., hasta llegar al Patio del Vergel donde se haría de nuevo visible. Tras el pabellón del claustro, surgiría de una pila, que a su vez la vertería mediante la gárgola estudiada a una gran alberca, o estanque, cuya cimentación podría, tal vez, tener algo que ver con la referida por Bujarrabal y Sancho.

En un tercer paso, el agua, a través de esa estructura que apareció en medio del jardín, y que nosotros consideramos más un sumidero en altura que una alberquilla (en el caso de que pertenezca al palacio y no a una fuente posterior, de tiempos del convento), se dirigiría de forma oculta por la canalización aparecida, al Salón del Aljibe, en cuyo centro todavía hoy quedan los restos de una fuente central $^{25}$. En esta última, brotaría un pequeño chorro que alcanzaría la cota más elevada de todo el sistema hidráulico (unos cuantos centímetros), mediante el principio de los vasos comunicantes.

Seguidamente toda la conducción finalizaría en el aljibe que da nombre a la estancia, bajo cuyo suelo aún hoy se encuentra. No olvidemos un hecho fundamental. Junto a dicho aljibe, y en una cota bastante inferior, se sitúan los baños del palacio, los cuales no podrían funcionar sin una buena reserva de agua que, después de ser usada, se arrojaría al río Duero.

Todos los estanques, como el propuesto, debían contar con dos sistemas de evacuación. Un sumidero superior, al que nos hemos referido anteriormente, por el que se vertería todo el sobrante de la alberca que rebasase la altura a la que se quería que llegase el agua, para evitar de esta forma los riesgos de inundación. Otro inferior posibilitaría su vaciamiento rápido, cuando fuera oportuno, para realizar trabajos de reparación o simplemente de limpieza. La explicación de haber ubicado un sumidero en el centro podía responder a que si se hubiera situado descentrado y hacia el propio Salón del Aljibe, irremediablemente se hubiese producido una corriente en la superficie del estanque, lo cual se intentaba evitar a toda costa, como pudimos comprobar por el complejo mecanismo de la gárgola conservada, destinada no a romper el efecto del espejo. No olvidemos que el estanque tendría una profundidad mínima al encontrarse muy próxima la roca madre sobre la que se construye todo el

${ }^{25}$ Circular de $124 \mathrm{~cm}$ de diámetro, decorada con azulejos verdes, blancos y negros, en forma de estrellas de ocho puntas unos y de aspa otros. Toda ella se encuentra en un cuadrado de mármol de 130 cm de lado. 
edificio. Al ser el centro del patio el lugar donde la tensión del líquido es menor, y el punto más equidistante a los lados de la alberca, pudo ser determinante para colocar allí el sumidero que aseguraba la cota máxima del agua ${ }^{26}$.

Lampérez, en su clásico estudio del monasterio, al tratar los baños, nos habla de la existencia de una tubería que procede del centro del claustro, cañería que se une a otra procedente de la cámara antigua (Salón del Aljibe), marchando después a desaguar al río. Una vez más, no podemos precisar la cronología de tales conducciones, pero se evidencia de nuevo que el sentido de circulación viene marcado por la diferencia de altura existente entre las estancias citadas, siendo los baños el último eslabón por el que pasa el agua antes de precipitarse al río. Seguramente esas dos conducciones de las que escribe Lampérez hagan referencia a esos sumideros necesarios a los que hemos hecho mención ${ }^{27}$.

Tras estudiar repetidamente todos estos datos llegamos a la siguiente conclusión (ver croquis ${ }^{28}$ ). Nos encontraríamos con un patio porticado en sus cuatro galerías, con arcos y pilares de ladrillo ${ }^{29}$, con pabellones enfrentados en sus lados menores, y una gran alberca cuadrangular en su centro. Tampoco nos parecería extraño que el arco central de las galerías mayores dispusiese de una luz mayor, permitiendo una visibilidad perfecta de los vanos de entrada a las estancias de las pandas norte y sur, al igual que sucede con todas las galerías de los principales palacios hispanomusulmanes y edificios meriníes conocidos ${ }^{30}$.

\footnotetext{
${ }^{26}$ Volvemos a insistir sobre la posibilidad de que toda esta estructura perteneciese a una fuente posterior realizada para el claustro del monasterio y no para el patio del palacio. Somos conscientes de la anormalidad en situar un sumidero en el centro del estanque si estudiamos otros ejemplos conocidos (albercas de los palacios de la Alhambra y edificios meriníes como el estanque de la zauia de la Chella de Rabat...), en los que el sumidero superior se suele poner en los bordes del estanque e incluso, como en el Patio de Comares, se aprovecha para crear conducciones visibles de agua junto a los arriates de vegetación. A pesar de ello, no debemos desechar esta solución, y es posible que pudiera influir algún otro factor, como el riesgo de inundación en caso de lluvias, o algo similar.

${ }^{27}$ Lampérez, V., "El Real Monasterio de Santa Clara de Tordesillas", B.S.C.E. 120 (1912), 584.

${ }^{28}$ En lo sucesivo todas las referencias que se hagan a los arcos, estancias u otros restos del edificio aparecen bajo números y letras, en el croquis presentado.

${ }^{29}$ Archivo del Convento de Santa Clara de Tordesillas, Caja 18, exp. 4.

Conjunto de documentos relacionados con los autos presentados en 1756, por la comisión nombrada por la Real Cámara para hacer informes sobre la necesidad de hacer obra en las celdas del Real Convento de Santa Clara de Tordesillas y no disponer el Convento de Fondos con que realizarlas. En estos papeles se hace mención al mal estado en que se encuentra el patio. En una vista ocular realizada por los maestros Manuel de Muelas y Francisco Aller de la galería del Claustro que se corresponde con la norte, se dice en un momento dado: «...pilares y arcos de ladrillo a la parte del mencionado Vergel que, por hallarse reventados, tienen sus abrazaderas y arcos de hierro...”. Documento sin foliar, inventariado por González Cristóbal, M., 1987, doc. n. ${ }^{\circ} 1319$.

${ }^{30}$ En las mismas obras de restauración, llevadas a cabo por Patrimonio Nacional en el edificio, sacaron a la luz el gran arco que comunicaba la crujía meridional del claustro con la estancia situada en la respectiva panda.
} 
La hipótesis que proponemos cohesionaría todos los restos arqueológicos aparecidos en la década pasada (cimentaciones del patio) y conservados en el monasterio (gárgola, pila y fuente del Salón del Aljibe), y por otra parte, tiene en cuenta la pendiente descendente existente entre el pozo, el Patio del Vergel, el aljibe y los baños.

Aunque casi de forma natural solemos tender a concebir los planteamientos de forma simétrica, en la solución que proponemos sólo se utilizaría una pila (la conservada, que ubicaríamos sobre la fuente del Salón del Aljibe —estancia 8, fuente $\mathrm{B}$ ), y el único canalillo conocido (que consideramos uniría el pabellón occidental con la alberca - croquis, A). No creemos viable que el estanque en su lado oriental tuviese otra gárgola semejante a la del extremo frontero, ya que en esta parte del patio el agua se dirige al aljibe, pareciendo de difícil comprensión que pudiera circular en sentido contrario, es decir, del Salón del Aljibe al centro del claustro. Más bien, todo parece apuntar que desde el sumidero central de la alberca y de forma oculta, a través de la conducción aparecida en la excavación de los años ochenta (a la que nos hemos referido repetidamente y que apareció en el eje longitudinal del patio, desde su centro a la panda oriental del mismo), el agua reaparecería en una posible fuente bajo el pabellón oriental y de nuevo, en la pila del Salón del Aljibe ${ }^{31}$. Si nos fijamos en la arquitectura de las casas y los palacios que se están realizando en el mundo nazarí, vemos que es muy común la existencia de albercas con una única entrada de agua, tal como aparece en las hipótesis del estado inicial del Palacio del Partal, Casa de Zafra, o del Palacio del Secano ${ }^{32}$.

El planteamiento propuesto explicaría que no apareciesen andenes con sentido $\mathrm{N}-\mathrm{S}$, completando el brazo ausente del supuesto crucero, tal como fue sugerido; y que la única conducción aparecida sólo fuera del centro del patio hasta la Sala del Aljibe.

Con el paso de los años y en tiempos del monasterio, aunque no sabemos cuándo, todo el sistema hidráulico del palacio se pierde. Los nuevos usos del edificio dejarían de utilizar los baños, y una gran comunidad se instalaría en el palacio de forma

${ }^{31}$ A esta última pila y desde el pabellón cercano, el agua también vendría de forma oculta, ya que los restos de dicha fuente en el Salón del Aljibe no parecen apuntar la entrada del agua por su parte superior. Más bien parece que aparecería por su centro mediante el sistema, ya aludido, de los vasos comunicantes.

${ }^{32}$ Orihuela Uzal, A., Casas y palacios nazaríes. Siglos XIII-XV, Barcelona, 1996. En este trabajo, tesis doctoral del autor, contamos, sin lugar a dudas, con la mejor y más completa investigación realizada sobre la arquitectura nazarí de los últimos años. Especialmente estimable es el enorme trabajo gráfico desplegado en dicho estudio, no sólo porque actualiza otros obsoletos, sino porque se presentan planimetrías e interesantes hipótesis de ciertos edificios por primera vez, trabajo en parte anunciado en su propio artículo "Los inicios de la arquitectura residencial nazarí, véase nota 12. 
permanente. La alberca no tendría ya sentido. El agua contaminada, tras pasar por la cocina conventual y las necesarias, evacuaría directamente al río.

De la documentación moderna (siglos XVIII-XIX) conservada en el archivo del monasterio, se puede deducir cómo todo el planteamiento primitivo ya no existe. Se habla de dos aljibes, uno exterior a la clausura (que estaría donde la actual huerta, y donde ubicamos el albercón o aljibe que se surtiría del pozo en tiempos de palacio) y otro interior (el del Salón del Aljibe). No hay comunicación entre ambas zonas, y como se refleja en dicha documentación, todos los años se dedicaba una parte del presupuesto de la comunidad al capítulo del "aljibe y tinajera", en donde se especifica que dicho aljibe, el del salón tantas veces citado, se llenaba una o dos veces al año, entre los meses de enero y febrero, mediante cántaras ${ }^{33}$.

\section{ESTANCIAS ADYACENTES AL PATIO DEL VERGEL}

No podíamos dejar de tratar, aunque de forma muy escueta, qué es lo que ocurre con todos los salones ubicados en las diferentes pandas del patio. A lo largo de los siglos todo el recinto se fue modificando. En la parte occidental se construyó en el siglo XVI el actual refectorio en tiempos de Felipe II (estancia 3). En su lado norte, los espacios medievales dieron paso a las actuales celdas construidas en el siglo XVIII. Al este queda el salón del aljibe, con su arco de ingreso (estancia 8, arco $\mathrm{H}$ ), decorado con yeserías, flanqueado por dos ventanas geminadas (lám. 6, ventanas I flanqueando el arco H), y limitado tanto al norte como al sur por dos grandes arcos tumidos (lám. 7, estancia $8, \operatorname{arcos} \mathrm{C}$ y D), conservando algo de sus atauriques el meridional. Al sur, encontramos el antecoro, Coro Largo, iglesia, sacristía, sotocoro y coro alto; fruto todo ello de las intervenciones sucedidas desde el siglo XV hasta el siglo XVIII (estancias 13, 10, $14,17,12,16$ ). Las galerías del claustro también se reformaron (siglos XVII-XVIII), bajo el período clasicista vallisoletano ${ }^{34}$.

\footnotetext{
${ }^{33}$ Son muchos los libros de distribución de rentas, conservados en el monasterio, sin inventariar, de los siglos XVII-XIX, en los que aparecen estos datos relativos al convento. Generalmente, se llenaba dicho aljibe una vez al año, salvo cuando el agua se corrompía por caer algún animal en él, o por otra circunstancia, quedando todo ello reflejado en dichos libros.

${ }^{34}$ J. L. Sancho, en dos artículos, se ha preocupado por ilustrarnos sobre los distintos trabajos realizados en las galerías del patio y en las celdas de la comunidad: "El Claustro del Vergel del Real Monasterio de Santa Clara de Tordesillas", Boletín del Seminario de Arte y Arqueología de Valladolid, LVII, 429-435; y "El Real Monasterio de Santa Clara de Tordesillas", La Arquitectura de los Sitios Reales. Catálogo Histórico de los Palacios, Jardines y Patronatos Reales del Patrimonio Nacional, Madrid, 1996, 591-602.
} 
En toda la parte meridional del edificio, a la que dedicaremos un próximo trabajo, tan sólo se conservan dos arcos de yeserías, en los lados norte y sur del Coro Largo ( $\operatorname{arcos} \mathrm{F}$ y G), ubicados en el eje transversal del Patio del Vergel, dos ventanas geminadas en ambos lados del arco que comunicaba esta estancia con el claustro (lám. 6, ventanas I a ambos lados del arco F); y un arco, decorado con yeserías en su rosca, en el extremo oriental del paramento de la crujía meridional del patio (lám. 8, arco E), que comunicaría con una sala que estaría donde la actual sacristía (estancia 12).

En el extremo suroccidental de toda esta parte del monasterio, se conserva la fachada del palacio, el vestíbulo repleto de ricas yeserías existente tras ella, y los restos de un arco, también decorado con atauriques, en el muro norte de la estancia alta, ubicada tras la misma portada (estancia 11).

Desde el artículo de Lampérez ${ }^{35}$, se sugirió la posibilidad de que en origen el palacio se articulase en torno al Patio del Vergel, mediante salones tripartitos, o tarbeas, tal como se denomina en Toledo a estos salones de planta rectangular central, rematados por alcobas cuadrangulares en sus extremos, siendo el Taller del Moro un buen ejemplo. Desde entonces, el resto de los autores que se han aproximado al edificio han mantenido la misma idea. Salvo la panda oriental, en donde se ha conservado el salón central (Salón del Aljibe), con los grandes arcos tumidos en sus extremos, no podemos decir que nos encontrásemos con similares soluciones en las otras crujías, ya que no nos han quedado restos que evidencien la articulación original.

Asimismo se ha defendido, desde el mismo artículo de $1912^{36}$, que la sacristía (estancia 12) podía ser uno de esos salones o alcobas que delimitaban los salones centrales. Hoy podemos decir que nada de lo que observamos en este espacio perteneció al palacio. Sus dos arcos apuntados, dispuestos en su lado norte (lám. 9, estancia 12, arcos J y K), de 3,10 m de luz, y separados por un machón de 1,10 $\mathrm{m}$ de ancho, nada tienen que ver con los vanos originales conservados por el otro lado, correspondientes al Salón del Aljibe (lám. 7, estancia 8, arco D) y crujía meridional del Patio del Vergel (lám. 8, crujía meridional, arco E). Estos dos últimos arcos, del siglo XIV, como se demuestra por los restos de atauriques que aún conservan, presentan una luz de $3,25 \mathrm{~m}$, el que comunica con el salón, y de 2,55 m el otro; estando ambos separados por 2,7 m. Si aún tuviésemos alguna duda, detrás del retablo que se dispone en el vano de la izquierda (lám. 9, estancia

${ }^{35}$ Op. cit., p. 586. En los trabajos ya aludidos de Bujarrabal y Sancho (p. 31-33), y de Pérez Higuera (p. 96), se apoya la misma idea defendida por Lampérez.

${ }^{36}$ Op. cit., p. 586. 
12, arco J), de dicho lado norte de la sacristía, pueden observarse restos de yeserías del palacio, que se situarían en el espacio de separación de los arcos originales. Esta estancia se empezaría a reformar a finales del siglo XIV o principios del siglo $\mathrm{XV}$, con la primera intención de construir sobre ella una cúpula parecida a la que cubre la Capilla Dorada, de dieciséis paños, por lo que se deduce de sus pechinas. Las obras terminaron por variar el proyecto previsto, introduciéndose finalmente la bóveda estrellada de crucería que vemos en la actualidad, y que dataríamos en tiempos de Juan II.

\section{A MODO DE CONCLUSIÓN}

En estudios anteriores hicimos hincapié en el protagonismo del rey Pedro I y su mujer María de Padilla en la construcción del palacio. Asimismo, escribimos sobre la relación existente entre el rey castellano y Muhammad V, amistad llena de intereses, que no sólo queda avalada por los hechos políticos, sino por los $\operatorname{artísticos}^{37}$. No cabe duda de que los ricos elementos conservados en este monasterio de Tordesillas vienen a demostrar, una vez más, esa dependencia artística de Castilla hacia Granada, en lo que se refiere al mundo de la arquitectura civil y en especial a la palatina. Si el palacio de Tordesillas se construye principalmente en la década de los cincuenta del siglo XIV, y el grueso de la Alhambra (Palacio de Arrayanes y de los Leones) en la década siguiente, tras la recuperación del reino por parte de Muhammad V en $1362^{38}$, gracias a la ayuda prestada por el rey castellano, se nos plantean las siguientes sugerencias.

Ya vimos cómo Torres Balbás apuntaba la idea de la posible vinculación del Patio de los Leones con los claustros monásticos y, en especial, con esos pabellones de lavabo junto a la entrada de sus refectorios. En Granada resultaba chocante, pero en la ribera del Duero, donde tantos y tantos edificios monásticos jalonan sus orillas, esta posibilidad resulta más creíble. Sin ir muy lejos, y citando tan sólo un ejemplo, en el monasterio cisterciense de Valbuena se encuentran los

\footnotetext{
${ }^{37}$ "Santa Clara de Tordesillas. Nuevos datos para su cronología y estudio. La relación entre Pedro I y Muhammad V", Reales Sitios 130 (1996), 32-40.

${ }^{38}$ Nos apuntamos a la corriente defendida por López López, A. C., y Orihuela Uzal, A., "Una nueva interpretación del texto de Ibn al-Jatīb sobre la Alhambra en 1362", Cuadernos de la Alhambra 26 (1990), 121-144, y por Cabanelas Rodríguez, D., "Cronología de las edificaciones de Muhammad V en la Alhambra", Realidad y símbolo de Granada, Bilbao, (1992), 189-204 y 349-350, línea de investigación que defiende que todo el palacio de los Leones de la Alhambra se construye en el segundo período de reinado del soberano nazarí, es decir, después de 1362.
} 
restos, del siglo XIII, de lo que fue, según los investigadores, un pabellón de lavabo de planta cuadrada, en el centro de la galería meridional de su claustro ${ }^{39}$.

En el verano de 1359 Muhammad V pierde el trono, tras el golpe de estado de su hermanastro Ismā'il II. El monarca se ve obligado a marcharse, dirigiéndose a la corte de Fez. En 1362 recupera de nuevo el poder gracias a la intervención de Pedro I, aunque el monarca ya había pasado el Estrecho tiempo antes. Durante ese período de tres años, buena parte de la corte nazarí se ve obligada a huir. Individuos de la personalidad de Ibn al-Jatīb marchan junto a su soberano; otros se establecieron en la corte del rey de Castilla. Fue muy variopinto el grupo que prefirió no salir de la Península, destacando hombres de ciencia, de literatura y altos cargos militares, que fueron bien recibidos por el hijo de Alfonso XI. Por ejemplo, el médico de Muhamammad V, Ibrāhīm Ibn Zarār, se trasladó a la misma corte de Pedro $\mathrm{I}^{40}$. ¿Pasaría algo similar con las cuadrillas de artesanos del rey granadino? Creemos que sí. Si vinieron literatos, científicos o militares, ¿qué de particular tendría que un soberano que compartía los principios estéticos de un monarca vasallo y amigo aprovechase la coyuntura para hacerse con los servicios de sus artífices? Algunos habrían trabajado ya para el monarca antes de 1359; lo que ocurre es que, después de ese año, su presencia sería incluso mayor, y seguramente vendrían los mejores artesanos.

Tal como defendimos en el trabajo que dedicamos a la cronología del palacio ${ }^{41}$, las obras se centraron en la década de los cincuenta, pudiéndose dilatar las mismas hasta 1361, año en que fallece María de Padilla. Alarifes granadinos, junto al trabajo decorativo del yeso, traerían la solución de utilizar una gran

${ }^{39}$ Antón, F., Monasterios medievales de la provincia de Valladolid, Valladolid, 1942, p. 43; Torres Balbás, L., Arquitectura gótica, Ars Hispaniae VII, Madrid, 1952, p. 143; Bango Torviso, I. G., "Arquitectura gótica", Arquitectura Gótica, Mudéjar e Hispanomusulmana, Historia de la Arquitectura Española II, Zaragoza, 1985, p. 444. Los pabellones de lavabo de los claustros cistercienses pueden mostrar muy diferentes plantas y ubicaciones. Los hay poligonales como en Poblet, Santas Creus, Veruela, Rueda o Alcobaça (Portugal). Respecto a los más próximos a Tordesillas (Matallana, Palazuelos, Valbuena y la Santa Espina), se han perdido todos salvo los restos del de Valbuena, y si los investigadores se inclinan a pensar que éste era de planta cuadrada, posiblemente la fórmula de los otros monasterios vecinos, y coetáneos, tuvieran una solución similar. Centrados en la galería, y de planta cuadrada, los encontramos en el monasterio zaragozano de Piedra; en Francia los tenemos en Fonteney y Silvacane, en Italia lo vemos en Fossanova, en Suiza lo hallamos en Bonmont, en Alemania en Schönow y Marienthal, etc. (Agradecemos al especialista en los monasterios cistercienses vallisoletanos medievales, don Antonio García Flores, que se encuentra realizando su tesis doctoral sobre el tema, los datos que reproducimos en esta nota.)

Por las cimentaciones aparecidas en Santa Clara de Tordesillas, nos encontraríamos ante unos pabéllones de grandes dimensiones, en sintonía con los conservados en los edificios monásticos. En Granada se refinaría la fórmula vallisoletana.

${ }^{40}$ Al-Abbadi, A. M., El reino de Granada en la época de Muhammad V, Madrid, 1973, 46-50.

${ }^{41}$ Véase n. 37. 
alberca en el centro del patio y, por otra parte, se harían eco de esos cercanos claustros monásticos y de sus pabellones de lavabo. De todas formas, no olvidemos que la solución del patio con sus cuatro galerías porticadas puede rastrearse desde la antigüedad, aunque en el mundo hispanomusulmán esta solución aparece en edificios de carácter público (mezquitas, Corral del Carbón, Maristán de Muhammad V...), pero nunca en casas o palacios nazaríes, en los que siguiendo la tradición anterior sólo se porticaban los lados menores.

Si los especialistas han terminado por desechar la existencia de los pabellones en Monteagudo, Tordesillas se convertiría en el precedente evidente e inmediato del celebérrimo Patio de los Leones. ¿Pudo llevar el esquema de Tordesillas a Granada alguno de esos maestros que trabajó junto al Duero? Una vez más, creemos que sí. La solución debió de gustarles y no sería extraño que, a su vuelta a la corte granadina, tras el restablecimiento de su monarca, hicieran uso de la fórmula desplegada en Santa Clara.

$\mathrm{Al}$ ser tantas las relaciones existentes entre las fechas y el patrocinio de todos estos edificios, es obligado que se estudien en conjunto. Ya que este palacio vallisoletano jamás hubiera sido posible sin los deseos de sus promotores, creemos justo que se estudie dentro de la arquitectura andalusí. Aunque tradicionalmente se le ha vinculado con los restos conservados en conventos y palacios de Toledo, vemos más ajustado relacionarlo con las obras que en estos momentos se están realizando en Granada y, si también se quiere, en Marruecos. Además, se puede decir que la práctica totalidad de los programas decorativos de la ciudad del Tajo que se pueden relacionar con Tordesillas, son siempre de cronología estrictamente coetánea o ligeramente posterior (Sinagoga del Tránsito, Casa de Mesa, casas del Conde de Cedillo...).

El canalillo, gárgola o surtidor que por primera vez se estudia en el presente trabajo, o las yeserías que aparecieron en el muro meridional del Coro Largo, sin olvidarnos de los baños, fachada, Capilla Dorada, Patio Árabe, conjuntos de yeserías distribuidos por todo el recinto, etc., obligan a que se estudien dentro del mismo capítulo edificios de la entidad del Alcázar de Sevilla, de la Alhambra y resto de los edificios medievales granadinos, sin olvidarnos de los palacios murcianos de los siglos XII-XIII, y de las manifestaciones meriníes del mismo período.

Seguramente, frente a criterios tan deterministas como los basados en el material, la mano de obra, la religión o la demarcación política, haya que ir reivindicando otros criterios más lógicos, y que en gran medida comienzan a introducirse en cierto sector de la historiografía medieval española, como son los que tienen en cuenta el estudio de los espacios, fuertemente unido a lo decorativo y lo funcional, a los promotores y su influencia en la configuración del gusto de 
un momento, y por supuesto, lo que llamaríamos circunstancias felices, que sobrepasando los límites de lo aparentemente normal, posibilitan la existencia de manifestaciones artísticas de difícil explicación.

Tal vez, tras el estudio del convento de Santa Clara, recuperemos un eslabón de la arquitectura andalusí que de alguna manera nos sirva para comprender todo un proceso que culmina en la Alhambra de Granada.

\begin{abstract}
This article presents a possible and inmediate predecessor of the Court of the Lions in the Alhambra of Grenade. The monastery of Santa Clara of Tordesillas (Valladolid) was an important palace built in the 1350's by Pedro I of Castile (1350-1369). Inside its walls there was a courtyard with pavilions emphasizing the main axis. A few years later, after 1362, Muhammad V (1354-1359, 1362-1391), a good friend of Pedro I, built the Palace and the Court of the Lions in the Alhambra. While a pool was constructed in Tordesillas in the middle of the patio, in Granada a cruciform garden was designed. In Pedro's palace the formula of pavilions will have been taken from the monumental bassins of the Cistercian monasteries near Tordesillas. The same pattern is likely to have been taken from Tordesillas to Granada by the same artists who worked for both kingdoms, thanks to the close friendship between the two kings.
\end{abstract}

\title{
RESUMEN
}

El presente trabajo muestra un posible e inmediato ejemplo precursor del Patio de los Leones de la Alhambra de Granada. El monasterio de Santa Clara de Tordesillas (Valladolid) fue un importante palacio construido por el rey de Castilla Pedro I (13501369) en la década de los cincuenta del siglo XIV. En su interior existía un patio con pabellones adelantados de su eje principal. Al poco tiempo, Muḥammad V (1354-1359, 1362-1391), amigo del rey castellano, erigió después de 1362 el Palacio y el Patio de Los Leones de la Alhambra. Mientras que en Tordesillas se dispuso una alberca en su centro, en Granada se optó por la solución del patio de crucero. La fórmula de los pabellones desplegada en el palacio de Pedro I tuvo que tomarse de los lavabos monumentales de los monasterios cistercienses cercanos. Gracias a las buenas relaciones existentes entre los dos monarcas, la solución pudo ser llevada de Tordesillas a Granada por artistas que estuvieran trabajando para los dos reinos. 
Croquis del monasterio de Santa Clara de Tordesillas.

Hipótesis del Patio del Vergel
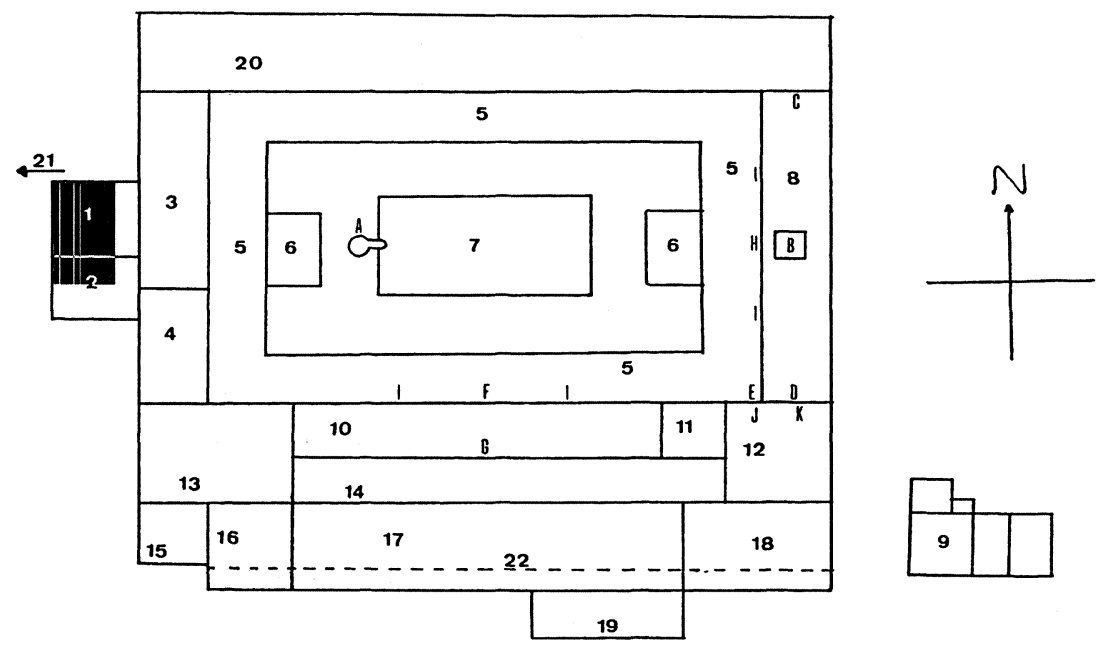

1. Capilla Dorada. Único resto conservado anterior al Palacio de Pedro I.

2. Patio Árabe. Reinado de Pedro I.

3. Refectorio. Reinado de Felipe II.

4. Estancias modernas

5. Crujías del Patio del Vergel. Siglos XVII-XVIII.

6. Pabellones propuestos (reinado de Pedro I) en el patio del Vergel correspondientes a las cimentaciones aparecidas en 1988.

7. Alberca propuesta. Reinado de Pedro I.

8. Salón del Aljibe. Reinado de Pedro I.

9. Baños. Reinado de Pedro I.

10. Coro Largo. Siglos XVII-XVIII.

11. Capilla. Bóveda del siglo Xv.

12. Sacristía. Siglo XV.

13. Antecoro. Siglos XVII-XVIII.

14. Capillas del Evangelio (ca. 1480-1510).

15. Fachada y vestíbulo decorado con yeserías. Reinado de Pedro I.

16. Coro y sotocoro. Siglo XVI, después de 1521 .

17. Cuerpo de la iglesia (ca. 1480-1510).

18. Cabecera (1449-1454).

19. Capilla del Contador Saldaña (1430-1435).

20. Celdas, y escaleras y en los extremos. S. XVIII.

21. Pozo (a unos $25 \mathrm{~m}$ de la Capilla Dorada).

22. Límite hipotético sur del palacio de Pedro I. Enrasando con el vestíbulo conservado $\left(n^{\circ}{ }^{15}\right)$.
A. Gárgola conservada, en la ubicación propuesta.

B. Fuente del Salón del Aljibe. En su centro podría estar la pila conservada.

C. Arco tumido en el testero norte del Salón del Aljibe. Hoy cegado.

D. Arco tumido, también cegado y similar al anterior, en el testero sur del Salón del Aljibe. Conserva restos de yeserías.

E. Arco de medio punto con restos de yeserías en su infradós.

F. Arcos de comunicación entre el Patio del Vergel y la estancia en la que hoy se encuentra el Coro Largo. Aparecido en 1988.

G. Arco de comunicación entre la estancia anterior $y$ el espacio ocupado hoy por las capillas del Evangelio.

H. Vano de acceso al Salón del Aljibe, decorado con yeserías.

I. Ventanas geminadas en las crujías oriental y meridional del patio del vergel.

Restos posteriores.

J, K. Arcos iguales correspondientes al lado norte de la sacristía. Siglo XV. 

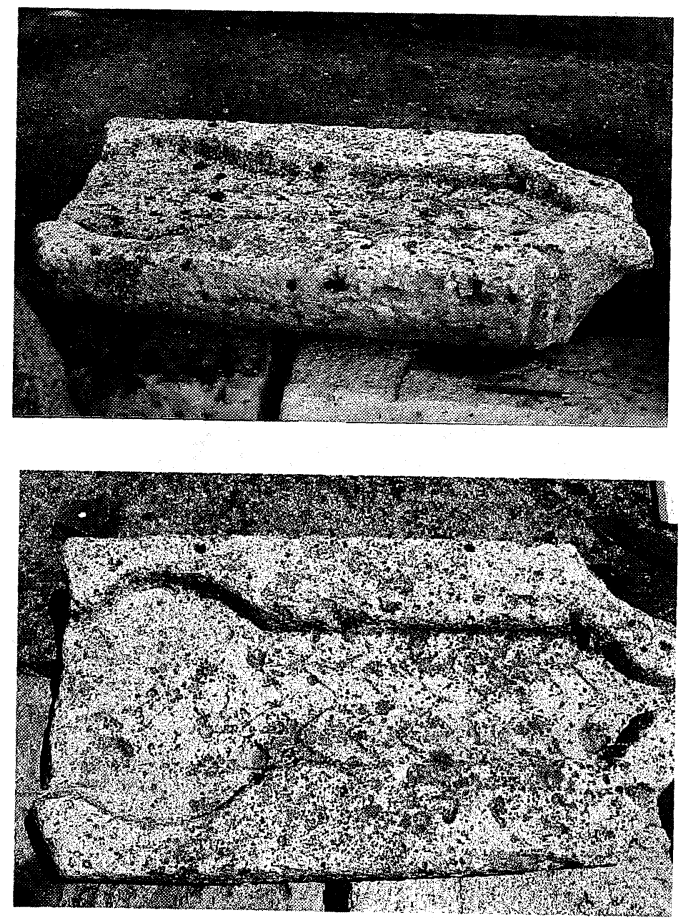

Láminas I y II. Canalillo o gárgola conservado en el monasterio.

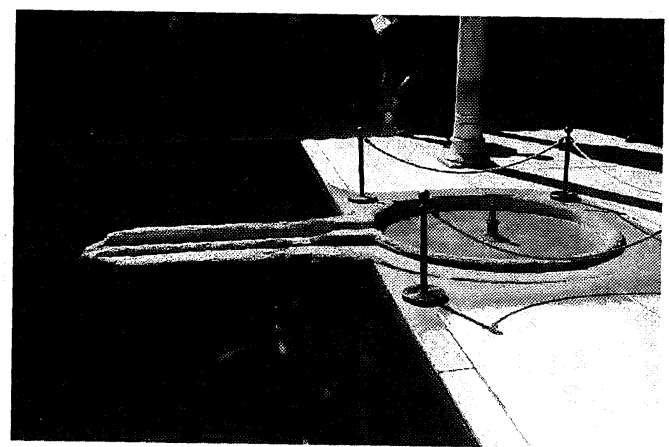

Lámina III. Pila y gárgola del lado norte del Patio de los Arrayanes de la Alhambra. 

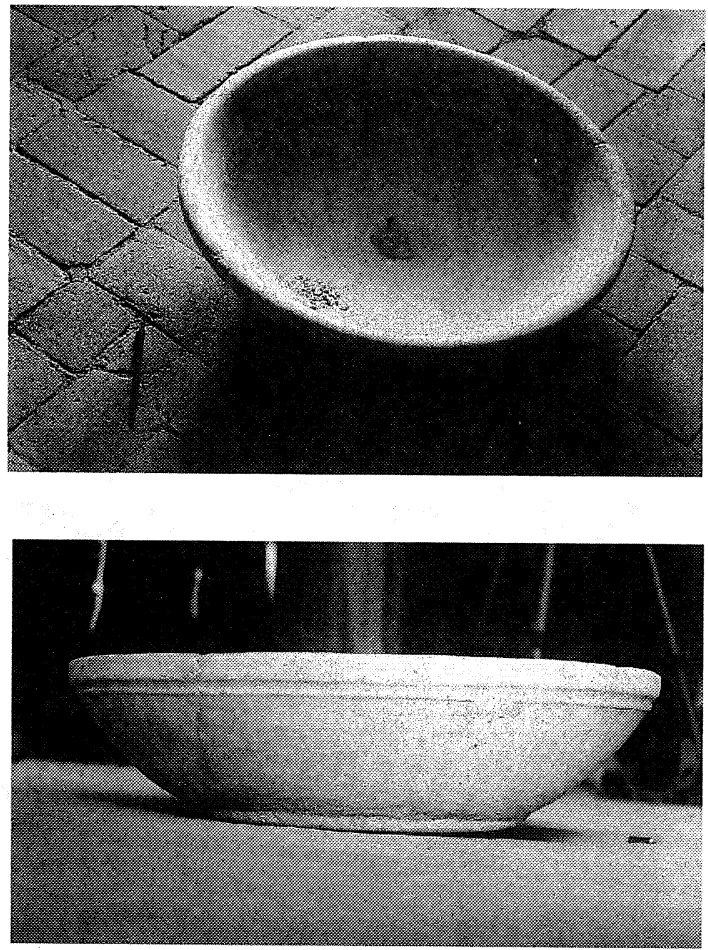

Láminas IV y V. Pila de mármol conservada en el monasterio.

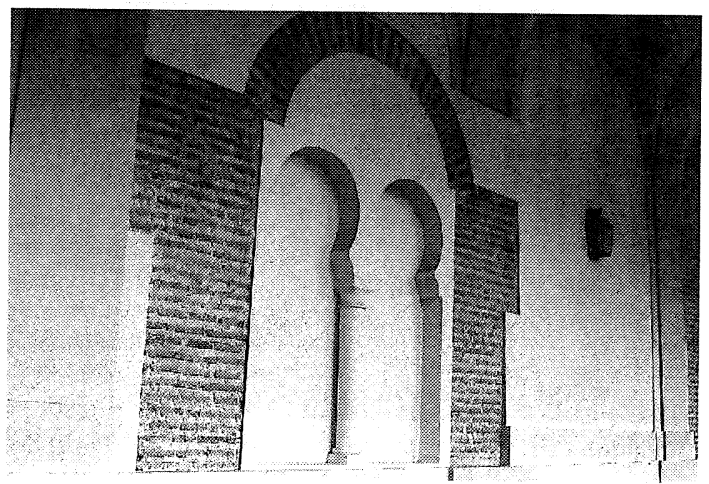

Lámina VI. Una de las cuatro ventanas geminadas (todas son iguales) aparecidas en las pandas oriental y meridional del Claustro del Vergel, flanqueando los vanos centrales de acceso a los salones principales de ambas pandas. 


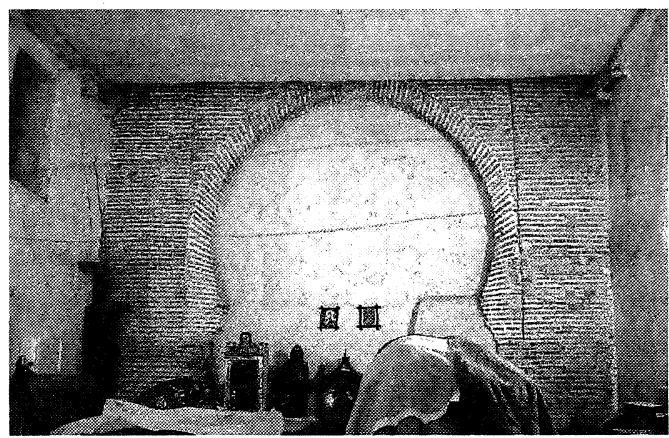

Lámina VII. Arco norte del Salón del Aljibe (el meridional es igual e incluso conserva algo de yeserías).

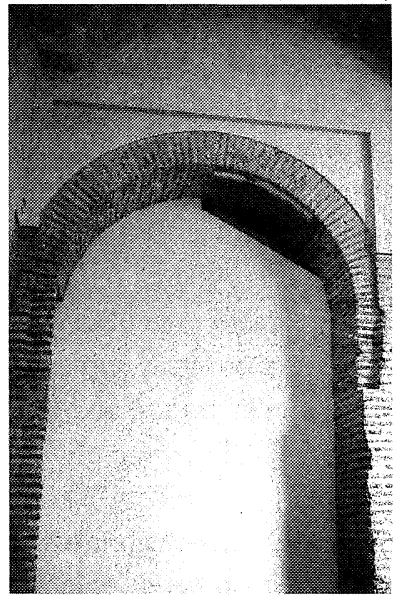

Lámina VIII. Arco del palacio con restos de yeserías en el extremo oriental de la crujía meridional del claustro del Vergel.

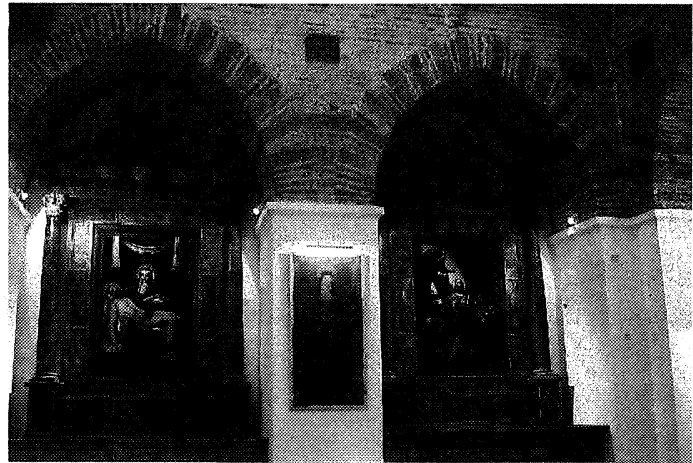

Lámina IX. Muro norte de la sacristía. 